\title{
Os produtos e processos educacionais dos programas de pós-graduação profissionais: proposições de um grupo de colaboradores
}

Ivanise Maria Rizzatti niserizzatti@gmail.com orcid.org/0000-0002-0982-2698 Universidade Estadual de Roraima (UERR), Boa Vista, Roraima, Brasi

\section{Andrea Pereira Mendonça} andrea.mendonca@ifam.edu.br Instituto Federal do Amazonas (IFAM), Manaus, Brasil

\section{Francisco Mattos}

francisco.mattos@gmail.com orcid.org/0000-0003-3760-4636 Janeiro, Brasil

\section{Giselle Rôças}

giselle.rocas@ifri.edu.br

rcid.org/0000-0002-1669-7725

Instituto Federal de Educação, Ciência e Tecnologia do Rio de Janeiro (IFRJ), Rio de Janeiro, Brasi

\section{Marcos André B Vaz da Silva} marcos.betemps@gmail.com orcid.org/0000-0002-1892-6595 Instituto Federal de Educação, Ciência e Tecnologia Sul-rio-grandense (IFSul), Pelotas, Rio Grande do Sul, Brasil

\section{Ricardo Jorge de S Cavalcanti} ricardo.cavalcanti@ifal.edu.br Instituto Federal de Alagoas (IFAL) Maceió, Alagoas, Brasil

Rosemary Rodrigues de Oliveira rosemary.oliveira@unesp.br orcid.org/0000-0002-1349-659X Universidade Estadual Paulista Júlio de Mesquita Filho (UNESP), Jaboticabal, São Paulo, Brasil

\section{RESUMO}

Uma das principais discussões em torno da modalidade profissional para a Área de Ensino reside na compreensão sobre o Produto Educacional (PE) e sua validação, considerando os critérios adotados pela CAPES para a Avaliação Quadrienal (2017-2020) da produção técnica-tecnológica (PTT). Em função dessa importância, durante o Seminário de Meio Termo da Área, em 2019, foram organizados Grupos de Trabalho (GT) de PE e Doutorado Profissional, que trabalharam de maneira integrada, com a finalidade de elaborar os conceitos em conjunto. A partir da definição de PE elaborada pela Área de Ensino, detalhamos algumas possibilidades de Produtos e Processos Educacionais que contemplam as tipologias já definidas em documentos da Área e que nesse trabalho foram organizadas tendo como referência o Relatório do GT Produção Tecnológica da CAPES de 2019. Assim, é apresentado neste artigo o relatório do GT com a compreensão sobre PE e uma proposta com critérios que visam à etapa de avaliação do Qualis Educacional. Com Seminário de Meio Termo e o estudo elaborado pelo relatório técnico da CAPES propomos um conjunto de conceitos que devem subsidiar a análise do PE. Esses conceitos são sintetizados em um modelo de formulário de validação com o objetivo de possibilitar uma validação unificada do PE por bancas de defesa de dissertação ou tese. Dessa forma, entendemos que uma discussão mais detalhada sobre PE pode conduzir a uma maior qualificação destes, permitindo que o trabalho desenvolvido nos Programas de Pós-graduação Profissionais tenha reflexos diretos na melhoria da Educação Básica.

PALAVRAS-CHAVE: Produtos Educacionais. Produção Técnica-Tecnológica. Programas de Pós-Graduação Profissionais. 


\section{INTRODUÇÃO}

A Área de Ensino, Área 46, foi criada por meio da Portaria CAPES no 83/2011, em 6 de junho de 2011, sendo constituída, naquele momento, por 60 cursos stricto sensu, distribuídos em nove cursos de Mestrado Acadêmico, 19 cursos de Doutorado e 30 cursos de Mestrados Profissionais. Sendo, assim, constituída de acordo com o Documento da Área de Ensino (2019), "a partir da nucleação dos programas da antiga Área de Ensino de Ciências e Matemática, criada em 2000, com apenas sete programas".

Nesses últimos 20 anos, o número de Programas na Área cresceu consideravelmente e hoje possui 230 cursos, distribuídos em 86 cursos de Mestrado e 40 de Doutorado na modalidade Acadêmico, 96 cursos de Mestrado e 8 cursos de Doutorado, modalidade Profissional, totalizando 187 Programas de Pós-graduação. Os Programas Profissionais já representam aproximadamente 52\% da Área de Ensino, que foi uma das pioneiras em ofertar cursos de Mestrado Profissional. Devido ao interesse da continuidade da formação dos mestres egressos nessa modalidade, os cursos de Doutorado Profissional (DP) já são uma realidade e um dos objetivos é atender essa demanda.

Na modalidade Profissional, diferentemente da modalidade Acadêmica, os discentes precisam desenvolver um Produto/Processo Educacional (PE) que necessita ser aplicado em um contexto real, podendo ter diferentes formatos. A incompreensão, pela comunidade acadêmica, das características da modalidade Profissional se tornou campo fértil de críticas e disputas. Ostermann; Rezende (2015) e Rezende; Ostermann (2015) tecem críticas aos Mestrados Profissionais (MP) de modo geral e aos Produtos Educacionais, de modo específico. As críticas das autoras se pautam em uma visão reducionista de que os MP e, por conseguinte, os PE gerados nessas esferas formativas se ancoram em um modelo de formação tradicional do professor, o que segundo as autoras, reflete e reforça a "tradição tecnicista da área de ensino" (OSTERMANN; REZENDE, 2015, p. 2). As autoras argumentam ainda que os PE oriundos desses Programas não são suficientes para solucionar os problemas da educação brasileira e, ainda, destacam que na área de ensino de Física - área de atuação das autoras - há profícua pesquisa em metodologias de ensino o que faz com que os PE desenvolvidos nos MP se configurem, nas palavras das autoras, como "mais do mesmo".

Em contraponto aos argumentos elaborados por Rezende; Ostermann (2015) e Ostermann; Rezende (2015), Rôças; Bomfim (2018) esclarecem que os PE não se configuram e nem devem ser vistos como receitas prescritivas capazes de serem acriticamente reproduzidas por outros docentes. A função de um PE desenvolvido em determinado contexto sócio-histórico é servir de produto interlocutivo à professores e professoras que se encontram nos mais diferentes contextos do nosso país. Os PE desenvolvidos no lócus dos MP não são imutáveis. Nos aventuramos a dizer, que por possuírem licenças Creative Commons e atenderem às cinco liberdades, estes produtos não estão totalmente prontos e/ou fechados.

Professores e professoras podem reusar (liberdade de usar), revisar (adaptar, modificar, traduzir), remixar (combinar dois ou mais materiais), redistribuir (compartilhar) e reter (ter a própria cópia) os diferentes produtos gerados nos MP de modo crítico, adaptando-os às necessidades de suas diferentes turmas de alunos e devolvendo à sociedade novos PE num continuum. 
Rôças e Bomfim (2018) destacam que o(a) professor(a) que busca a modalidade de Mestrado e/ou Doutorado Profissional, é instado não apenas a desenvolver produtos e/ou técnicas mas a "compreender a sua prática de maneira mais reflexiva", na medida em que esses programas, do mesmo modo que os acadêmicos com profícua pesquisa na área de metodologias de ensino, buscam formar docentes capazes de elaborar perguntas de pesquisa que emergem de sua prática, apreendendo referenciais teórico-metodológicos capazes de auxiliá-los a problematizá-la. Nas palavras dos autores "O PE deve surgir a posteriori, nesse processo, sendo (minimamente) testado na realidade para o qual foi previsto e pensado, e pode ocorrer após a confecção do produto ou dar origem a ele" (RÔÇAS; BOMFIM, 2018, p. 5). É preciso destacar também o caráter compulsório do $P E$, pois

\begin{abstract}
por força de lei, a modalidade profissional necessita estabelecer uma interlocução com demais setores da sociedade, extrapolando os muros da academia e promovendo "transferência de tecnologia" científica e/ou cultural, bebendo na fonte da pesquisa aplicada, além de ampliar o tempo de exposição e reflexão do profissional aos referenciais teórico-metodológicos de cada área de conhecimento (RÔÇAS; MOREIRA, PEREIRA, 2018, p. 61).
\end{abstract}

Desde a publicação da Portaria Normativa MEC no 17 de dezembro de 2009, que padronizou e regulamentou a criação de cursos novos submetidos à CAPES e de acompanhamento dos cursos profissionais em funcionamento, a área de Ensino se debruçou na tarefa de compreender as dimensões da pesquisa aplicada e do desenvolvimento de PE no âmbito dos Programas Profissionais simultaneamente ao crescimento de programas dessa modalidade. A estratégia de escuta e plenárias realizada a cada Seminário de Acompanhamento, garante um processo mais transparente e democrático de discussão, lócus que emergiu e vem consolidando a natureza dos PE como principal produção de um Programa Profissional.

Embora o conceito venha sendo construído ao longo dos anos de existência da área de Ensino, conforme podemos verificar nos documentos norteadores e que constam da Memória da Área, nem sempre foi completamente assimilado pelos pesquisadores diretamente ligados a essa modalidade. Assumimos como hipóteses para essas incompreensões o fato da formação da maioria do corpo docente dos PPGs ter ocorrido em cursos da modalidade acadêmica, aliada ao desconhecimento dos documentos norteadores por parte dos professores quanto alunos dos programas.

Outro problema identificado ao longo das avaliações está relacionado a dificuldade de registro dessa produção nos sistemas de coleta da CAPES e no Lattes, sendo fatores que dificultam a identificação e divulgação dos PE. Uma conquista da área foi a elaboração da Classificação de Produção Técnica em 2016 (BRASIL, 2016), o que possibilitou o registro na Plataforma Sucupira da produção dos diversos materiais educativos, consolidando a discussão até então acumulada, permitindo a qualificação e avaliação desses produtos na quadrienal 2013-2016, fato até então inédito.

À partir do 5o Seminário de Acompanhamento (2017) a área iniciou a reestruturação do Qualis Educacional, e por meio das mudanças de registro na Plataforma Sucupira, apontou para a necessidade de definições mais claras e objetivas para avaliar os PE gerados nos Programas. Em 2019, no Seminário de Meio Termo, a Área define os conceitos sobre a Produção Técnica dos Programas 
Profissionais e assume de forma clara e objetiva a possibilidade de que Produto e Processo Educacional estão interligados, informando no Documento de Área que um PE é

um processo ou produto educativo e aplicado em condições reais de sala de aula ou outros espaços de ensino, em formato artesanal ou em protótipo. Esse produto pode ser, por exemplo, uma sequência didática, um aplicativo computacional, um jogo, um vídeo, um conjunto de vídeo-aulas, um equipamento, uma exposição, entre outros. A dissertação/tese deve ser uma reflexão sobre a elaboração e aplicação do produto educacional respaldado no referencial teórico metodológico escolhido (BRASIL, 2019a, p. 15).

Cabe ainda um destaque relativo à criação dos DP, curso que necessita explicitar melhor essa relação Tese/PE, considerando a complexidade desse Produto/Processo que será gerado no âmbito do DP. Salienta-se que a necessidade de um PE não possuía uma concepção e exigências claras no início dos cursos em 2000. Os MP vão se construindo ao longo de sua existência, ajustando não só o entendimento, mas as estruturas de seu funcionamento (MARQUES et al., 2020). Da mesma forma, o PE sempre foi evidenciado como algo essencial para esses Programas (MOREIRA; NARDI, 2009) e sua concepção vem sendo consolidada e melhor estabelecida quando se analisa cronologicamente os documentos da área de Ensino na CAPES.

Dessa forma, considera-se PRODUTO/PROCESSO EDUCACIONAL (PE) na Área de Ensino, o resultado tangível oriundo de um processo gerado a partir de uma atividade de pesquisa, podendo ser realizado de forma individual (discente ou docente Stricto Sensu) ou em grupo (caso do Lato Sensu, PIBID, Residência Pedagógica, PIBIC e outros). O PE deve ser elaborado com o intuito de responder a uma pergunta/problema oriunda do campo de prática profissional, podendo ser um artefato real ou virtual, ou ainda, um processo (BESSEMER; TREFFINGER, 1981). Deve apresentar, em sua descrição, as especificações técnicas, ser compartilhável, registrado em plataforma, apresentar aderência às linhas e aos projetos de pesquisa do PPG, apresentar potencial de replicabilidade por terceiros, além de ter sido desenvolvido e aplicado para fins de avaliação, prioritariamente, com o público-alvo a que se destina.

Ao considerar a definição de PE expressa anteriormente, detalha-se algumas possibilidades de Produtos/Processos que estão enquadrados na Área de Ensino. É importante ressaltar que tais definições foram tomadas com base no GT de Produção Técnica da CAPES, ampliando, portanto, a tipologia já descrita no Documento de Área.

Nesses termos, definem-se como:

- Tecnologia Social: método, processo ou produto transformador, desenvolvido e/ou aplicado na interação com a população e/ou apropriado por ela, que represente solução para inclusão social e melhoria das condições de vida, com características de atividades de extensão;

- Material Didático: produto de apoio/suporte com fins didáticos na mediação de processos de ensino e aprendizagem em diferentes contextos educacionais (impressos, audiovisuais e novas mídias);

- Software/Aplicativo (Programa de computador): software é um conjunto de instruções ou declarações a serem usadas direta ou indiretamente por um 
computador, a fim de obter um determinado resultado. Ele é composto por um código-fonte, desenvolvido em alguma linguagem de programação;

- Manual/Protocolo: conjunto das informações, decisões, normas e regras, que se aplica a determinada atividade, que enseja os conhecimentos básicos de uma ciência, uma técnica, um ofício ou procedimento. Pode ser um guia de instruções que serve para o uso de um dispositivo, para correção de problemas ou para o estabelecimento de procedimentos de trabalho. No formato de compêndio, livro/guia pequeno ou um documento/normativa, impresso ou digital, que estabelece como se deve atuar em certos procedimentos;

- Processo educacional - descrição das etapas empreendidas no processo de ensino e aprendizagem, com intencionalidade clara e com o objetivo de criar oportunidades sistematizadas e significativas entre o sujeito e um conhecimento específico. Oportuniza um mapeamento e uma superação do senso comum, levando o sujeito a compreender que o conhecimento é advindo da produção humana, sendo resultado de investigações que envolvem os domínios e aspectos científicos, tecnológicos, históricos e/ou sociais, não sendo, portanto, neutro.

Tais categorias contemplam as tipologias já previstas em documentos da área de Ensino desde 2013 (BRASIL, 2013; 2017), e que foram reorganizadas de acordo com o Relatório do Grupo de Trabalho Produção Tecnológica da CAPES (BRASIL, 2019b), descritas a seguir:

i. Material didático/instrucional: são propostas de ensino, envolvendo sugestões de experimentos e outras atividades práticas, sequências didáticas, propostas de intervenção, roteiros de oficinas; material textual, como manuais, guias, textos de apoio, artigos em revistas técnicas ou de divulgação, livros didáticos e paradidáticos, histórias em quadrinhos e similares, dicionários; mídias educacionais, como vídeos, simulações, animações, videoaulas, experimentos virtuais e áudios; objetos de aprendizagem; ambientes de aprendizagem; páginas de internet e blogs; jogos educacionais de mesa ou virtuais, e afins; entre outros;

ii. Curso de formação profissional: atividade de capacitação criada e organizada, inclui cursos, oficinas, entre outros;

iii. Tecnologia social: produtos, dispositivos ou equipamentos; processos, procedimentos, técnicas ou metodologias; serviços; inovações sociais organizacionais; inovações sociais de gestão, entre outros;

iv. Software/Aplicativo: aplicativos de modelagem, aplicativos de aquisição e análise de dados, plataformas virtuais e similares, programas de computador, entre outros;

v. Evento Organizados: ciclos de palestras, exposições científicas, olímpiadas, expedições, feiras e mostras científicas, atividades de divulgação científica, entre outros;

vi. Relatório Técnico;

vii. Acervo: curadoria de mostras e exposições realizadas, acervos produzidos, curadoria de coleções, entre outros; 
viii. Produto de comunicação: produto de mídia, criação de programa de rádio ou TV, campanha publicitária, entre outros;

ix. Manual/Protocolo: guia de instruções, protocolo tecnológico experimental/aplicação ou adequação tecnológica; manual de operação, manual de gestão, manual de normas e/ou procedimentos, entre outros;

x. Carta, mapa ou similar.

As tipologias descritas acima são reflexo de PE que já foram declarados por PPGs em avaliações anteriores, e não excluem outros modelos ou perfis que não estejam aqui elencados e que possuam justificativas nos projetos específicos dos programas.

\section{METODOLOGIA DO PRODUTO/PROCESSO EDUCACIONAL}

Foi destacada, por ambos os grupos de trabalho estabelecidos no último seminário de área (2019 - GT Produtos/Processos Educacionais e GT Doutorado Profissional), a necessidade de que as dissertações e teses da modalidade Profissional apresentassem uma seção metodológica para a pesquisa desenvolvida e uma subseção (ou seção específica) destinada a metodologia de desenvolvimento do PE. Assim, as dissertações e teses deverão conter no corpo do texto uma seção ou capítulo, abordando a metodologia de desenvolvimento do PE: 1) contendo a descrição das etapas de delimitação do problema a ser abordado; 2) definições das etapas, idealização e elaboração do PE; 3) prototipagem (quando for o caso); 4) aplicação, avaliação, validação (1 1 a instância, mínimo recomendado para o MP), e; 5) análise à luz do referencial teórico e metodológico. Espera-se que os PE resultantes dos MP atinjam plenamente a 1 a instância, o que não impede que o mesmo produto tenha a continuidade do desenvolvimento pelo egresso e docente nos grupos de pesquisa dos Programas e que resultariam em produções bibliográficas diversas.

É importante destacar a compreensão de dois conceitos que comumente estão circunscritos ao cotidiano de quem elabora e reflete sobre as etapas de desenvolvimento do $\mathrm{PE}$, prototipagem e validação, a saber:

PROTOTIPAGEM- elaborar uma situação/artefato que simule o funcionamento do $\mathrm{PE}$, com o objetivo de testar a funcionalidade e/ou usabilidade por parte do usuário.

VALIDAÇÃO- respaldado em Cook e Hatala (2016), a Área de Ensino compreende que a validação de produto/processo consiste em identificar evidências que permitam avaliar a adequação e a interpretação de resultados desse (produto/processo), a partir de critérios previamente estabelecidos. Essa coleta de evidências pode se dar a partir de instrumentos qualitativos e/ou quantitativos para avaliar a adequação da utilização, interpretação e resultados da sua aplicação. A proposição dos autores é a de que a validação ocorra em duas instâncias distintas.

A primeira instância deve ocorrer durante a aplicação do PE, sendo recomendado para o curso de MP e obrigatória para DP, sendo exemplos de instrumentos de validação: grupos focais, narrativas, pesquisas de opinião, juízes 
especialistas e outros. Essa etapa de validação deve informar qual foi o nível de envolvimento dos participantes na tentativa de melhor entenderem o conteúdo subjacente ao PE de que fizeram parte (os participantes precisam conhecer previamente como participarão tendo em conta os aspectos éticos pertinentes à pesquisa); permite identificar os participantes e em que nível ocorreu a participação e a adesão no desenvolvimento do produto/processo (o que levou à transformação, elaboração do PE), possibilita identificar quem poderá ser os potenciais participantes futuros e em que nível estes poderão participar ou aderir ao emprego do produto/processo elaborado; além de informar qual o tempo empregado durante o desenvolvimento do produto/processo e em qual campo profissional mostrou-se como suficiente aos participantes. Esse processo de avaliação e de validação deve estar descrito e diretamente relacionado ao referencial teórico e teórico-metodológico escolhido para o processo de investigação.

A segunda instância de validação é obrigatória para todos e será feita pela banca de defesa de dissertação ou tese, com base no instrumento de validação proposto ao longo desse ensaio, tendo sido desenvolvido a partir de propostas que já estão em uso por alguns PPGs e tendo sido aprovado na plenária de coordenadores do Seminário de Área de 2019 (BRASIL, 2019c). Ainda nesse caso, a banca pode indicar o potencial de desenvolvimento contínuo do PE até que atinja a fase da Replicabilidade, item obrigatório ao DP. As etapas para o desenvolvimento do PE estão ilustradas na Figura 1 e como pode ser observado, há uma diferenciação entre PE desenvolvido no Mestrado e no Doutorado Profissional. 
Figura 1 - Etapas de desenvolvimento do Produto/Processo educacional. Elaborado por Marcella Sarah Filgueiras de Farias ${ }^{3}$ e Andréa Pereira Mendonça ${ }^{4}$.

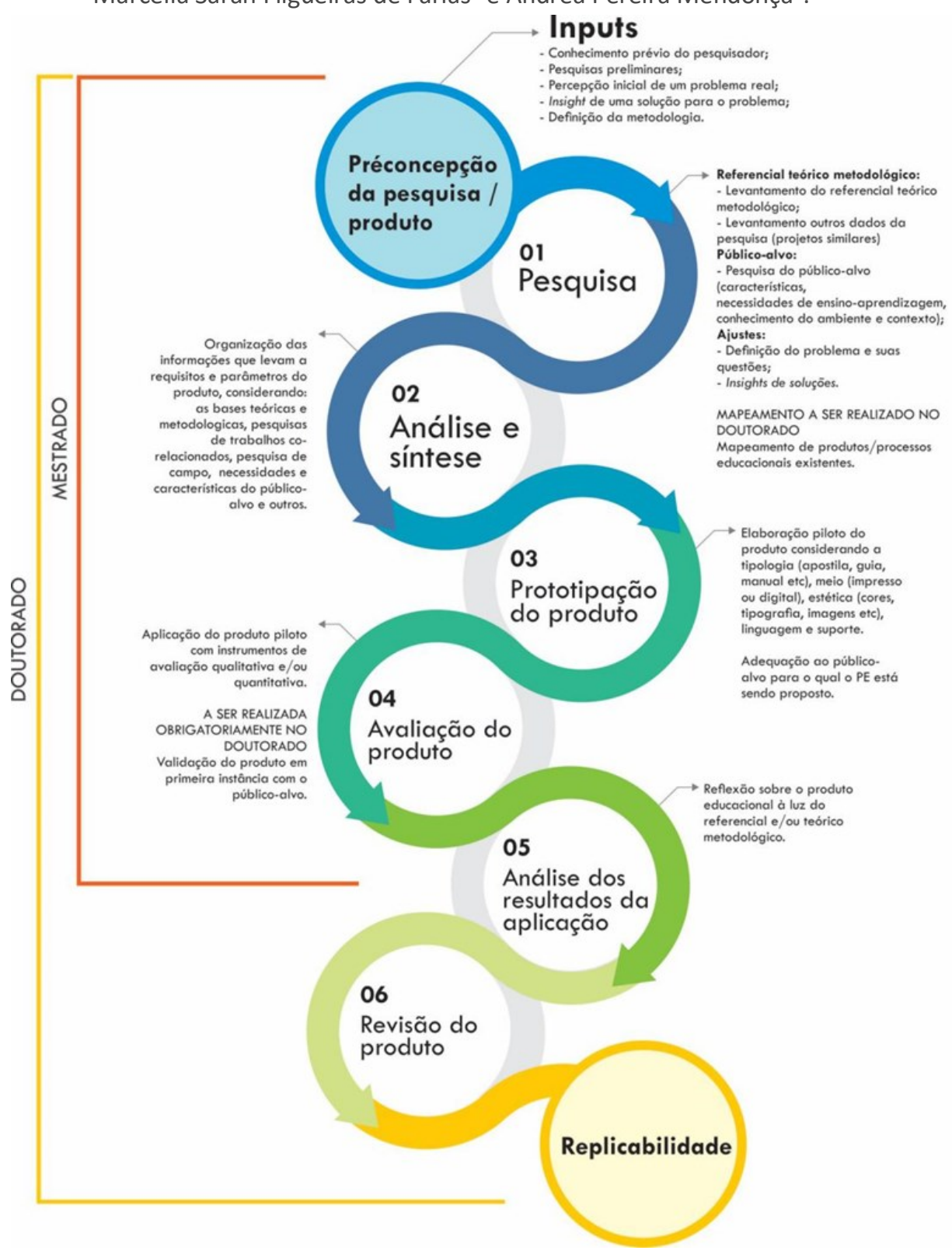

Fonte: Farias e Mendonça (2019).

As etapas 1 a 5 são comuns a ambos os níveis de cursos da modalidade Profissional, com caráter de recomendação ou obrigatoriedade dependendo do nível, conforme descrito na etapa 4 - avaliação do produto. A etapa 5 é de extrema importância, sendo um dos momentos durante o desenvolvimento da pesquisa que o professor/profissional refletirá de forma orientada e sustentada na teoria sobre sua prática e solução proposta em seu trabalho. Essa relação com a produção do conhecimento não é novidade e possibilita que o professor deixe de ser apenas um reprodutor, atuando também como um agente de reflexão e produção de materiais educacionais. Batista, Mocrosky e Mondini (2017) falam dessa relação entre sujeito e objeto na produção de conhecimento em seu artigo, sendo possível fazer tal transposição para a relação entre a modalidade profissional e o desenvolvimento do produto/processo educacional. 
Rôças, Moreira e Pereira (2018, p. 67) defendem que o

principal produto de um curso de MP não é o PE em si, mas sim o processo de transformação do mestrando durante a elaboração do PE. O mestrando, autor do PE, envolve-se no processo de identificação do problema (de ordem prática), com base em referencial teórico-metodológico consistente e coerente, reflete, propõe encaminhamentos / soluções para abordar o problema identificado, aplica e testa o PE, retomando criticamente a primeira versão para compor a versão final que acompanha o texto dissertativo.

Esse percurso possibilita que o professor reflita para além das etapas teóricas e metodológicas da sua pesquisa, mas em especial sobre sua ação pedagógica, buscando (re)direcionar sua prática (SELINGARDI, MENEZES, 2017). Outro ponto a ser destacado é relacionado ao egresso do MP que pode iniciar o desenvolvimento do PE nessa fase inicial de formação continuada, dando sequência, robustez e consolidação de todas as etapas previstas na figura 1 ao terminar o seu DP e/ou dar continuidade a aplicação de seu produto em outras esferas.

\section{DIMENSÕES DO PRODUTO/PROCESSO EDUCACIONAL}

Podemos compreender as dimensões do PE como macro características que devem ser consideradas desde a etapa de elaboração até a validação em segunda instância, formada por uma banca qualificada em sessão pública de defesa de dissertação ou tese, composta por doutores especialistas, com aderência comprovada à Área de Ensino da CAPES, sendo considerada como etapa de validação para o Qualis Educacional.

Os autores defendem que haja uma proposição de uma ficha de avaliação e validação do PE pela área de Ensino, a qual deve ser preenchida pela banca examinadora e disponibilizada pelo PPG em conjunto com o PE. A banca avaliará a Dissertação ou a Tese emitindo uma ata, e analisará o PE com emissão deste documento, o qual deve ser considerado como o documento de validação por pares especializados. Uma ficha de avaliação uniformizada auxiliará na avaliação dos PE analisados para o Qualis Educacional, um avanço da área de Ensino, conforme apontado por Araújo-Jorge, Sovierzoski e Borba (2017).

A defesa para uma ficha unificada segue a escuta ativa sobre pleito feito por vários coordenadores de Programas no Seminário realizado pela área de Ensino em 2019. Não sendo algo inédito para alguns Programas dessa modalidade na Área de Ensino. Aqui apresentamos uma proposição, com base no que outros programas apresentaram no seminário. Percebemos ao longo dos anos que as bancas de defesa focam excessivamente na dissertação, avaliando pouco (ou nada) o $P E$, sendo por vezes compostas por docentes/pesquisadores que não vivenciam a área de Ensino/Educação, ou ainda, com pouca ou nenhuma experiência/aproximação com a modalidade profissional, portanto sem pleno conhecimento dos critérios de avaliação e da caracterização dos Programas Profissionais. Essa cultura precisa mudar, pois os PE são a principal produção dos MP e DP, sendo que nesse último nível de curso o PE ganha um espaço mais sofisticado. Assim, é importante que no momento de constituição das bancas de defesas os elementos acima sejam considerados, além de informar os membros da banca sobre o teor das fichas de avaliação de um PE. 
Analisando o relatório técnico da CAPES sobre produção técnica (BRASIL, 2019b, d) e comparando os conceitos lá expostos com a expertise dos autores e suas leituras, propomos os seguintes conceitos, os quais devem ser considerados na análise do $P E$, são eles:

COMPLEXIDADE - compreende-se como uma propriedade do produto/processo educacional relacionada às etapas de elaboração, desenvolvimento e/ou validação. Na Área de Ensino, entende-se que a complexidade é uma dimensão do PE a ser contabilizada no Qualis Educacional a partir do modelo de avaliação desenvolvido pela Área para ser emitido pela banca de dissertação ou tese.

REGISTRO - refere-se a uma catalogação do PE, na qual podem fornecer informações sobre direitos autorais, propriedade intelectual, ou ainda, sigilo (ISBN, ISSN, registro em bibliotecas, licença Creative Commons e outras).

IMPACTO - considera-se nesse quesito a forma como o PE foi utilizado e/ou aplicado nos sistemas educacionais, culturais, de saúde ou CT\&I. Esse dado será avaliado pelas bancas de defesa de dissertação ou tese a partir do modelo de validação proposto para a Área de Ensino, objetivando a compreensão do motivo para a criação do $\mathrm{PE}$, a relevância, o foco de aplicação do Produto, permitindo, com efeito, avaliar em qual área a mudança pode ser percebida. É importante reconhecer se a demanda foi espontânea ou contratada e qual é a área impactada pela proposição (educacional, cultural, de saúde ou CT\&I).

APLICABILIDADE - relaciona-se à facilidade de acesso e propriedade de aplicação do PE, para que seja acessado e utilizado de forma integral e/ou parcial em diferentes sistemas. A propriedade de aplicação refere-se ao processo e/ou artefato (real ou virtual) e divide-se em três níveis: 1) aplicável (quando o PE tem potencial de utilização direta, mas não foi aplicado); 2) aplicado (quando o PE foi aplicado uma vez, podendo ser na forma de um piloto/protótipo); 3) replicável (o PE está acessível e sua descrição permite a utilização por terceiros considerando a possibilidade de mudança de contexto de aplicação). Compreende-se, portanto, que para o curso de MP, o PE deve ser aplicável e é recomendado que seja aplicado. Enquanto para o DP, o Produto deve ser aplicável e ter sido aplicado e, é recomendado que seja replicável. Para a área de Ensino, esse conceito será avaliado a partir de dois critérios no Qualis Educacional, a saber: acesso e aplicabilidade (avaliado a partir do modelo de validação a ser emitido pela banca).

ADERÊNCIA - compreende-se como a origem do PE a fim de apresentar origens nas atividades oriundas das linhas e dos projetos de pesquisas do PPG stricto sensu em avaliação. Como considera-se na área de Ensino a produção do docente de maneira integral, eventuais PE elaborados em conjunto com discentes de PIBIC, PIBID, Residência Pedagógica, ou ainda de outras tipologias, a partir de suas origens, que poderão não atender a esse critério em sua totalidade, pois não terão obrigatoriamente aderência às linhas e aos projetos de pesquisa do programa de pós-graduação Stricto Sensu.

INOVAÇÃO - considera-se a amplitude desse conceito. A área de Ensino define-o a partir das práticas cotidianas, assumindo-se como um PE elaborado a partir de algo novo, ou da reflexão/modificação de algo já existente revisitado para a/em prol da realidade estudada (BESSEMER; TREFFINGER, 1981). A propriedade de inovação refere-se ao processo ou ao artefato (real ou virtual) e divide-se em 
três níveis, conforme proposto no Relatório Inovação e Transferência de Conhecimento (BRASIL, 2019d):

1) $P E$ de alto teor inovador (desenvolvimento com base em conhecimento inovador);

2) PE com médio teor inovador (combinação/compilação de conhecimentos pré-estabelecidos);

3) PE com baixo teor inovador (adaptação de conhecimento existente). Esse dado será avaliado pelas bancas de defesa de dissertação ou tese, a partir do modelo de validação proposto para a área de Ensino.

Ainda nesse sentido, Inovação não deriva apenas do PE em si, mas da sua metodologia de desenvolvimento, do emprego de técnicas e recursos para tornálo mais acessível, de utilizá-lo em contexto social, dentre outros. Entende-se que a inovação (tecnológica, educacional e/ou social) no ensino está atrelada a uma mudança de mentalidade e/ou a um modo de fazer de educadores, gestores, alunos e egressos. São exemplos de inovação: conscientização sobre cidadania e meio ambiente, modernização do espaço escolar, melhoria na rotina gerencial, aplicação de temas de vanguarda, etc.

De posse desses conceitos, considerando a experiência prática durante a Quadrienal de 2017, e nas discussões acumuladas nos Seminários de Área de 2017 e 2019, propõe-se à área de Ensino a adoção de um modelo de ficha de validação (Quadro 1), a qual poderá ser implementada para análise dos PE defendidos na modalidade profissional. Essa proposição foi aprovada na plenária do último Seminário de Área, e tem por objetivo possibilitar uma validação unificada pelas bancas de defesa de dissertação e tese. Essa ficha poderá (a critério do discente e do orientador) ser considerada como uma opção de 1ạ instância de validação para PE elaborados no MP e, como 2 a instância de validação, para aqueles oriundos do DP. Importante frisar, que a Área aprovou a aplicação dessa ficha para a qualificação dos PE no Qualis Educacional (Quadriênio de 2021-2024) e que pode constar da documentação anexada na Plataforma Sucupira nas informações complementares sobre Produção Técnica-Tecnológica. 
QUADRO 1 - Proposta de Ficha de Avaliação de Produto/Processo Educacional para a segunda instância de validação

IES:

Discente:

Título da Dissertação/Tese:

Orientador:

Coorientador (se houver):

FICHA DE VALIDAÇÃO DE PRODUTO/PROCESSO EDUCACIONAL (PE)

Complexidade - compreende-se como uma propriedade do PE relacionada às etapas de elaboração, desenvolvimento e/ou validação do Produto Educacional. * Mais de um item pode ser marcado.

Aplicabilidade - relaciona-se ao potencial de facilidade de acesso e compartilhamento que o PE possui, para que seja acessado e utilizado de forma integral e/ou parcial em diferentes sistemas.

PE foi utilizado e/ou aplicado nos sistemas educacionais, culturais, de saúde ou CT\&I. É importante destacar se a demanda foi espontânea ou contratada.

\begin{tabular}{|c|c|}
\hline $\begin{array}{c}\text { Aplicabilidade - relaciona-se ao } \\
\text { potencial de facilidade de acesso e } \\
\text { compartilhamento que o PE possui, } \\
\text { para que seja acessado e utilizado de } \\
\text { forma integral e/ou parcial em } \\
\text { diferentes sistemas. }\end{array}$ & $\begin{array}{r}\text { ( ) PE tem características de aplicabilidade a } \\
\text { partir de protótipo/piloto, mas não foi } \\
\text { aplicado durante a pesquisa. }\end{array}$ \\
$\begin{array}{c}\text { ( ) PE tem características de aplicabilidade a } \\
\text { partir de protótipo/piloto e foi aplicado } \\
\text { durante a pesquisa, exigível para o doutorado. }\end{array}$ \\
$\begin{array}{c}\text { ( ) PE foi aplicado em diferentes } \\
\text { ambientes/momentos e tem potencial de } \\
\text { replicabilidade face à possibilidade de acesso e } \\
\text { descrição. }\end{array}$ \\
$\begin{array}{c}\text { Acesso - relaciona-se à forma de } \\
\text { acesso do PE. }\end{array}$ \\
$\begin{array}{c}\text { ( ) PE com acesso via rede fechada. } \\
\text { ( ) PE com acesso público e gratuito. }\end{array}$ \\
\hline
\end{tabular}

( ) A metodologia apresenta clara e objetivamente a forma de aplicação e análise do PE.

( ) Há uma reflexão sobre o PE com base nos referenciais teóricos e teórico-metodológicos empregados na respectiva dissertação ou tese.

( ) Há apontamentos sobre os limites de utilização do PE.

( ) Protótipo/Piloto não utilizado no sistema relacionado à prática profissional do discente.

( ) Protótipo/Piloto com aplicação no sistema Educacional no Sistema relacionado à prática profissional do discente.

( ) O PE é concebido a partir da observação e/ou da prática do profissional e está atrelado à questão de pesquisa da dissertação ou tese. 
FICHA DE VALIDAÇÃO DE PRODUTO/PROCESSO EDUCACIONAL (PE)

\begin{tabular}{|c|c|}
\hline & $\begin{array}{l}\text { ( ) PE com acesso público e gratuito pela } \\
\text { página do Programa. } \\
\text { ( ) PE com acesso por Repositório institucional } \\
\text { - nacional ou internacional - com acesso } \\
\text { público e gratuito. }\end{array}$ \\
\hline $\begin{array}{c}\text { Aderência - compreende-se como a } \\
\text { origem do PE apresenta origens nas } \\
\text { atividades oriundas das linhas e } \\
\text { projetos de pesquisas do PPG em } \\
\text { avaliação. }\end{array}$ & $\begin{array}{c}\text { ( ) Sem clara aderência às linhas de pesquisa } \\
\text { ou projetos de pesquisa do PPG stricto sensu } \\
\text { ao qual está filiado. } \\
\text { ( ) Com clara aderência às linhas de pesquisa } \\
\text { ou projetos de pesquisa do PPG stricto sensu } \\
\text { ao qual está filiado. }\end{array}$ \\
\hline $\begin{array}{l}\text { Inovação - considera-se que o PE é/foi } \\
\text { criado a partir de algo novo ou da } \\
\text { reflexão e modificação de algo já } \\
\text { existente revisitado de forma } \\
\text { inovadora e original. }\end{array}$ & $\begin{array}{l}\text { () PE de alto teor inovador (desenvolvimento } \\
\text { com base em conhecimento inédito). } \\
\text { ( ) PE com médio teor inovador (combinação } \\
\text { e/ou compilação de conhecimentos pré- } \\
\text { estabelecidos). } \\
\text { ( ) PE com baixo teor inovador (adaptação de } \\
\text { conhecimento(s) existente(s)). }\end{array}$ \\
\hline \multicolumn{2}{|c|}{ Breve relato sobre a abrangência e/ou a replicabilidade do PE) } \\
\hline \multicolumn{2}{|l|}{ Assinatura dos membros da banca: } \\
\hline \multicolumn{2}{|l|}{ Presidente da banca: } \\
\hline \multicolumn{2}{|l|}{ Membros internos: __ } \\
\hline \multicolumn{2}{|l|}{ Membro externos: } \\
\hline Data da defesa: & \\
\hline
\end{tabular}

Fonte: Autoria própria (2019). 


\section{CONSIDERAÇÕES FINAIS}

A adoção de critérios de elaboração e validação de Produtos/Processos Educacionais (PE) que valorizam métodos de pesquisa como: a escolha e apreensão de referencial teórico-metodológico que fundamentem as metodologias de ensino; formas de avaliação e seleção de conteúdos que sustentarão a elaboração da dissertação/tese e do PE; bem como a fase de revisão do Produto, ancorada em análise crítica das etapas científicas, retira de cena a visão instrumental que a academia ainda possa ter sobre os Programas Profissionais, evidenciando o papel formativo dos mesmos.

A perspectiva de formação stricto sensu na modalidade Profissional tem sido valorizada ao mesmo tempo em que se consolida esta modalidade de cursos. $\mathrm{Na}$ área do Ensino, devemos cuidar para que a produção intelectual, na forma de PE, e na reflexão sobre essa produção, possa efetivamente oportunizar momentos de debates e transformações na Educação Básica. Desta forma, entendemos que uma discussão cada vez mais detalhada sobre os PE pode nos conduzir a uma qualificação maior destes.

Faz-se necessário ampliar o debate sobre Inovação, Aplicação e Impacto dos $\mathrm{PE}$, compartilhando com as demais áreas a expertise acumulada pela Área de Ensino nas últimas duas décadas sobre desenvolvimento e avaliação de PE, sem desconsiderar a preocupação constante em não somente qualificar o trabalho desenvolvido nos Programas de Pós-graduação Profissionais. Mas, principalmente, fazer com que este trabalho reflita diretamente na Educação Básica em nosso País, pois a grande finalidade dos MP e DP continua a ser a vocação para a pesquisa de $\mathrm{PE}$, principalmente para atender às demandas sociais, prioritariamente para a Educação Básica.

Seria ingênuo de nossa parte pensar que todos os problemas da Educação Básica serão resolvidos por meio dos PE gerados nos PPG Profissionais. Entretanto, ao considerar a abrangência e localização desses programas, precisamos refletir sobre o impacto deles para a formação de professores/profissionais, na produção de pesquisas voltadas para diferentes contextos, além da mudança de postura sobre o processo de construção do conhecimento na sala de aula ou em espaços não formais. Talvez, seja necessário avaliar como dar maior visibilidade aos PE produzidos nos PPG profissionais, da mesma forma que damos publicização aos artigos em periódicos da Área.

Considerando que os PPGs são lócus de formação de recursos humanos, ressaltamos que o principal "produto" da modalidade profissional é o professor/profissional que termina os cursos da área, pois eles estão aptos a refletirem sobre suas práticas a partir de um referencial teórico metodológico, identificando situações-problema e propondo soluções - o PE. Portanto, as dissertações e teses são as narrativas sobre os percursos percorridos e o PE elaborado. E nesse contexto podemos afirmar que a produção que emana dos programas profissionais não se trata de uma reprodução tecnicista, e sim a materialização de uma análise crítica sobre diferentes contextos profissionais relacionados ao Ensino, pautada na reflexão e utilização de referenciais teóricos e metodológicos. 


\title{
The educational products and processes of professional postgraduate programs: proposals from a group of employees
}

\begin{abstract}
One of the main discussions around the professional modality for the Education Area is the understanding about the Educational Product (PE) and its validation considering the criteria adopted by CAPES for the four-year (2017-2020) evaluation of the technical-technological production (PTT). Due to this importance, during the midterm seminar of the Area, in 2019, Work Groups (WG) of PE and Professional Doctorate were organized, which worked in an integrated manner, in order to elaborate the concepts together. Based on the definition of PE elaborated by the Education Area, we detailed some possibilities of Educational Products and Processes that contemplate the typologies already defined in documents of the area and that in this work were organized having as reference the Report of the Technological Production WG of CAPES of 2019. Thus, this article presents the report of the WG with the understanding about PE and a proposal with criteria aimed at the evaluation stage of Educational Qualis. Based on the experience accumulated by the Education Area, the discussions on PE held at the mid-term seminar and the study prepared by the technical report of CAPES, we propose a set of concepts that should support the analysis of PE. These concepts are synthesized in a model validation form with the objective of enabling a unified validation of PE by dissertation or thesis defense boards. Thus, we understand that a more detailed discussion on Educational Products can lead to a greater qualification of these, allowing the work developed in the Professional Postgraduate Programs to have direct reflections on the improvement of Basic Education.
\end{abstract}

KEYWORDS: Educational Products. Technical-technological production. Professional Postgraduate Programs. 


\section{AGRADECIMENTOS}

Agradecemos a todos os coordenadores que estiveram presentes no Seminário de Área de Ensino realizado na CAPES em 2019 e que contribuíram com sugestões e compartilhamentos de experiências, anseios e possíveis soluções.

\section{NOTAS}

1. Doravante, assumimos a sigla PE para designar tanto o Produto quanto o Processo educacional.

2. Exemplos de registro: ISNB, ISSN, registro em bibliotecas, licença Creative Commons e outras possibilidades.

3. Egressa do Programa de Pós-Graduação em Ensino Tecnológico (PPGET) - IFAM.

4. Orientadora do trabalho em tela, docente permanente do Programa de PósGraduação em Ensino Tecnológico (PPGET) - IFAM.

\section{REFERÊNCIAS}

ARAÚJO-JORGE, T. C.; SOVIERZOSKI, H. H.; BORBA, M. de C. A Área de Ensino após a avaliação quadrienal da CAPES: reflexões fora da caixa, inovações e desafios em 2017. Revista Brasileira de Ensino de Ciência e Tecnologia, v. 10, n. 3, 2017. Disponível em: https://periodicos.utfpr.edu.br/rbect/article/view/7744. Acesso em: 04 jun. 2020.

BATISTA, J. O.; MOCROSKY, L. F.; MONDINI, F. Sujeito e objeto na produção do conhecimento científico. ACTIO, Curitiba, v. 2, n. 3, p. 44-59, out./dez. 2017.

BESSEMER, S. P; TREFFINGER, D. J. Analysis of creative products: review and synthesis. The Journal of Creative Behavior, v. 15, n. 3, p. 158-178. 1981.

BRASIL, CAPES. Documento de Área - Ensino, Brasília, 2013.

BRASIL, CAPES. Considerações sobre Classificação de Produção Técnica - Área de Ensino, Brasília, 2016.

BRASIL, CAPES. Documento de Área - Ensino. Brasília, 2017.

BRASIL, CAPES. Documento de Área - Ensino. Brasília, 2019a.

BRASIL, CAPES. Grupo de trabalho Produção Técnica. Brasília, 2019b.

BRASIL, CAPES. Relatório do Seminário de Meio Termo - Área de Ensino. Brasília, 2019c.

BRASIL, CAPES. GT Inovação e Transferência de Conhecimento. Brasília, 2019d.

COOK, D. A; HATALA R. Validation of educational assessments: a primer for simulation and beyond. Advances in simulation, v. 31, n. 1, p. 2-12, 2016. 
FARIAS, M. S F.; MENDONÇA, A. P. Imagem elaborada no Grupo de Trabalho Produto Educacional da Área de Ensino da CAPES. Brasília, Set. 2019.

MARQUES, N. L. R.; DA SILVA BUSS, C.; MÜLLER, M. G.; DA SILVA; M. A. B. V. Concepções a respeito do Trabalho Final do Mestrado Profissional em Ensino de Ciências. Revista Educar Mais, 4(1), 172-187, 2020.

MOREIRA, M. A.; NARDI, R. O mestrado profissional na área de ensino de ciências e matemática: alguns esclarecimentos. Revista Brasileira de Ensino de Ciência e Tecnologia, v. 2, n. 3, 2009.

OSTERMANN, F.; REZENDE, F. Os mestrados profissionais em ensino das ciências da natureza no Brasil. Ciênc. educ. (Bauru), v. 21, n. 3, p. I-III, 2015. Disponível em: http://www.scielo.br/scielo.php?script=sci_arttext\&pid=S1516-

73132015000300001\&lng=pt\&nrm=iso. Acesso em: 04 jun. 2020.

REZENDE, F.; OSTERMANN, F. O protagonismo controverso dos mestrados profissionais em ensino de ciências. Ciênc. educ. (Bauru), v. 21, n. 3, p. 543-558, 2015. Disponível em:

http://www.scielo.br/scielo.php?script=sci_arttext\&pid=S1516-

$73132015000300002 \&$ Ing=pt\&nrm=iso. Acesso em: 04 jun. 2020.

RÔÇAS, G.; BOMFIM, A. M. do. Do embate à construção do conhecimento: a importância do debate científico. Ciênc. educ. (Bauru), v. 24, n. 1, p. 3-7, 2018. Disponível em: http://www.scielo.br/scielo.php?script=sci_arttext\&pid=S1516$73132018000100003 \&$ Ing=pt\&nrm=iso. Acesso em: 04 jun. 2020.

RÔÇAS, G.; MOREIRA, M. C. A.; PEREIRA, M. V. "Esquece tudo o que te disse": os mestrados profissionais da área de ensino e o que esperar de um doutorado profissional. Revista ENCITEC, v. 8, n. 1, p. 59-74, 2018. Disponível em: http://srvapp2s.urisan.tche.br/seer/index.php/encitec/article/view/2624. Acesso em: 04 Jun. 2020.

SELINGARDI, G.; MENEZES, M. V. M. Compreendendo o que é ser um professor reflexivo ante a ação pedagógica. ACTIO, Curitiba, v. 2, n. 3, p. 270-286, out./dez. 2017.

Recebido: 26 jun. 2020

Aprovado: 04 ago. 2020

DOI: $10.3895 /$ actio.v5n2.12657

Como citar:

RIZZATTI, I. M.; MENDONÇA, A. P. MATTOS, F ; RÔÇAS, G SILVA, M. A. B V da; CAVALCANTI, R. J.

S.; OLIVEIRA, R. R. Os produtos e processos educacionais dos programas de pós-graduação profissionais:

proposições de um grupo de colaboradores. ACTIO, Curitiba, v. 5, n. 2, p. 1-17, mai./ago. 2020. Disponível

em: <https://periodicos.utfpr.edu.br/actio>. Acesso em: XXX

Correspondência:

Ivanise Maria Rizzatti

Rua Sete de Setembro, n. 231, Bairro Canarinho, Boa Vista, Roraima, Brasil.

Direito autoral: Este artigo está licenciado sob os termos da Licença Creative Commons-Atribuição 4.0

Internacional.

(c) (i) 